\title{
Correction to: Ultra-low-power bulk-driven fully differential subthreshold OTAs with partial positive feedback for $G_{m}-C$ filters
}

\author{
Tripurari Sharan $^{1}$ (1) $\cdot$ Priyanka Chetri $^{1} \cdot$ Vijaya Bhadauria $^{2}$
}

Published online: 9 February 2018

(C) Springer Science+Business Media, LLC, part of Springer Nature 2018

\section{Correction to: Analog Integr Circ Sig Process}

https://doi.org/10.1007/s10470-017-1065-5

The original version of this article unfortunately contained a mistake. The presentation of Fig. 3 was incorrect. The correct version of Fig. 3 is given below.

Fig. 3 The subthreshold FD-OTA, having bulk-driven FVF input core with partial positive feedback and current mirror self-cascode load

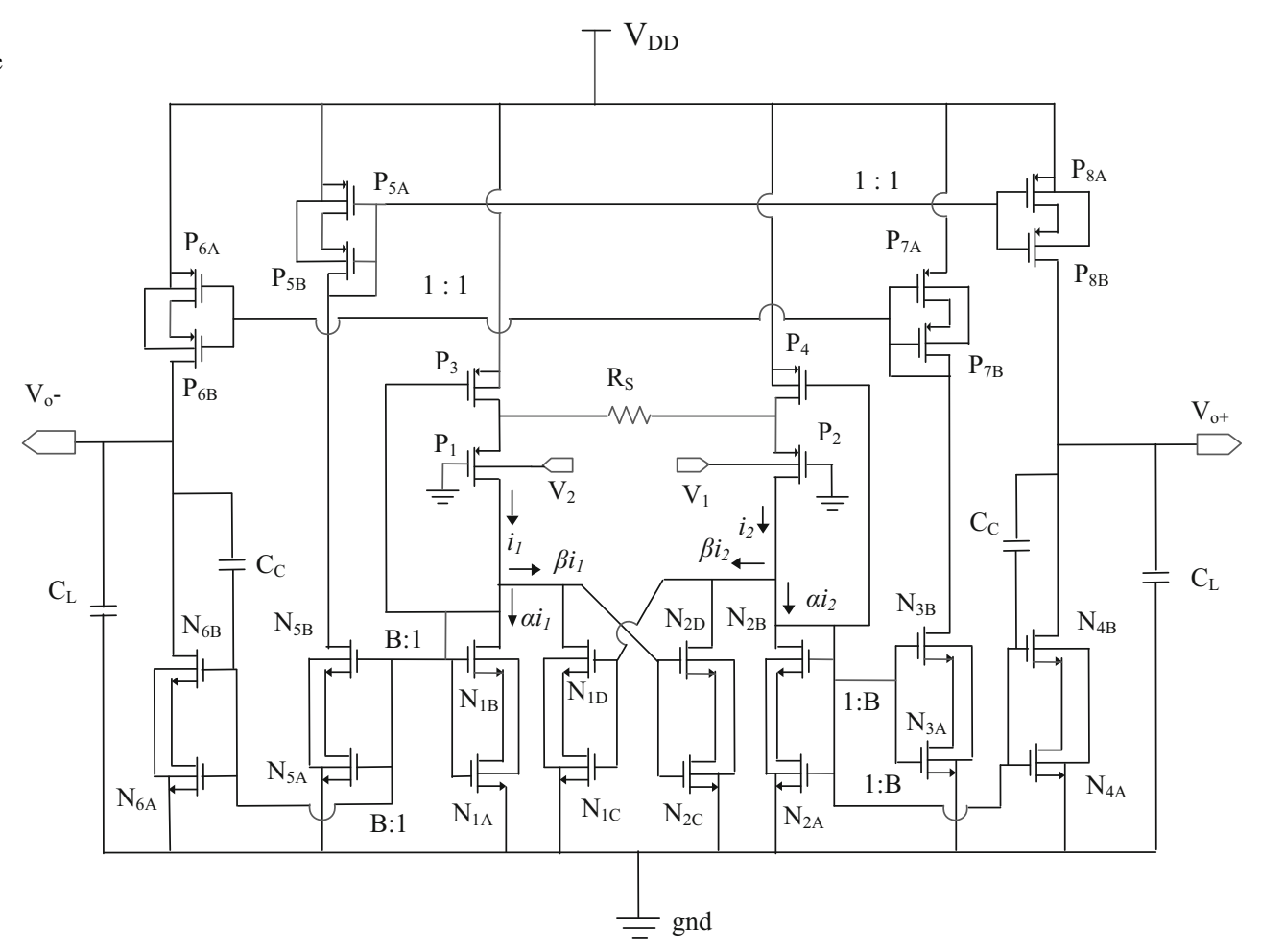

The original article can be found online at https:// doi.org/10.1007/s10470-017-1065-5.

Tripurari Sharan

tsh1962mzp@gmail.com

Priyanka Chetri

priyankachetri17@gmail.com

Vijaya Bhadauria

vijaya@mnnit.ac.in
ECE Department of North Eastern Regional Institute of Science and Technology, Nirjuli, Arunachal Pradesh 791109, India

2 ECE Department of Motilal Nehru National Institute of Technology, Teliyar Ganj, Uttar Pradesh 211004, India 